\title{
The Research of Teaching Quality Appraisal Model Based on AHP ${ }^{\mathrm{a}}$ Kong Liu'an, ${ }^{\mathrm{b}}$ Wang Xiaomei , ${ }^{\mathrm{b}}$ Yang Lin \\ ${ }^{\mathrm{a}}$ Henan University of Urban Construction Pingdingshan City, Henan Province, China 467000 \\ ${ }^{\mathrm{b}}$ Henan Polytechnic University Jiaozuo City, Henan Province, China 454000
}

\begin{abstract}
According to facts and databases of teaching in institutions of higher education, based on analyzing systematically to effect elements in teaching estimation of quality, by means of AHP model, the research constructs a series of systematic appraisal system of teaching quality in colleges and universities in order to evaluate the quality of teaching more accurately in a whole.
\end{abstract}

Index Terms: Teaching Quality ; AHP Model ; In colleges and universities

(C) 2012 Published by MECS Publisher. Selection and/or peer review under responsibility of the International Conference on E-Business System and Education Technology

\section{Introduction}

With the expand enrollment of colleges and universities as well as the scale of higher education unceasing expansion, the problems between expanding scale and quality guarantee attract much attention. It is key step for controlling personnel training quality in high schools to carry on effective evaluation for teaching quality. The paper establishes appraisal index system for teaching quality, sets up AHP model of teaching quality index appraisal, and makes comments on teaching quality for teachers in colleges and universities. The result states this assessment method is objective and feasible.

\section{AHP Model Theory}

The Analytic Hierarchy Process (AHP) is a multi-criteria decision-making approach for combination of qualitative and quantitative analysis which was developed by Thomas L. Saaty of American's famous operational research expert in the 1970s. The feature of AHP is established a hierarchy structure model when the essence, influence factor, and internal relationship of complicated decision question have been analyzed deeply. Then it uses less rational information making mathematics of decision-making thought process. So that it provides simple decision way for solving sophisticated decision-making problems in multiple goal, multi-criterion or no structure [1]. 
It divides for 4 steps to apply AHP for modeling. (1) Setting up a hierarchy process. The actual problem is divided for goal, criteria and scheme level. (2) Making up all judgment matrixes for each level. That is all elements of same level process paired comparisons with the importance of criterion for above level, and then construct comparative judgment matrixes. (3) Calculating relative weight between compared factor and this criterion according to judgment matrix, and processing consistency check. (4) Computing the weight of order importance between the level and it's relative elements for elements of the above level, and making reorder and decision.

\section{Teaching quality system of evaluation}

\section{1 The constructive principle of teaching quality system of evaluation}

1) Combination of goal and complexity. The system of evaluation of teaching quality must embody requirement with teaching works and personnel training to high schools from country. It must abide by education rule and reflect teaching goal of colleges and universities completely.

2) Combination of scientificity and practicability. Scientificity refers that appraisal index needs to accord with teaching rule. The relationship among indexes could form the organized whole which correlates with each other as well as does not conflict to each other. Practicability is not only convenient operation, but also links tightly detail target of evaluation.

The system of evaluation that meets professional characteristic for teachers in colleges and universities is made up in proceed from actual conditions [2].

3) Combination guidance within pertinence. Guidance states that it is embodied by teaching guidance idea, the development direction of teaching reform correctly. Meanwhile, it has leadership function that mirrors teaching rules. Pertinence should grasp existent teaching quality problem in class for teachers in the different phrases, and set up assess index and standard punctually.

\section{2 System of evaluation of teaching quality [3]}

1) Teaching attitude: Lesson plan and draft of speech prepare well before class. Giving a lesson with exciting; Serious for teaching, modest manner; Treat students equality; Teachers can listen to students' suggestion carefully, and have responsibility.

2) Teaching ability: vivid language, systematical in ideas, giving prominence to the key points; Using teaching methods and measures reasonably; Blackboard-writing tidy, applying multi-media rightly; Make goods use of time in class.

3) Teaching effect: The study interest from students could be stimulated. Higher effect in class; Have guidance meaning for practice. The quality and ability for students will be improved.

\section{AHP Model Project of Teaching Quality}

\section{1 Setting up hierarchical structure}

According to the above index system, the hierarchical model for establishing teaching quality assessment is showed in table 1 [4]. 
Table 1 System of evaluation for teaching quality in colleges and universities

\begin{tabular}{|c|c|c|}
\hline Target Level & Criteria Level & Index Level \\
\hline \multirow{9}{*}{$\begin{array}{l}\text { Comprehensive } \\
\text { appraisal of teaching } \\
\text { Quality in colleges } \\
\text { and universities } \\
\text { A }\end{array}$} & $\begin{array}{l}\text { Teaching } \\
\text { attitude B1 }\end{array}$ & $\begin{array}{l}\text { Lesson plan and draft of speech prepare well before class. Giving a lesson } \\
\text { with exciting C11 }\end{array}$ \\
\hline & & Serious for teaching, modest manner $\quad \mathrm{C} 12$ \\
\hline & & Treat students equality $\mathrm{C} 13$ \\
\hline & & $\begin{array}{l}\text { Teachers can listen to students' suggestion carefully, and have } \\
\text { responsibility. C14 }\end{array}$ \\
\hline & $\begin{array}{l}\text { Teaching ability } \\
\text { B2 }\end{array}$ & $\begin{array}{l}\text { Vivid language, systematical in ideas, giving prominence to the key points } \\
\text { C21 }\end{array}$ \\
\hline & & Using teaching methods and measures reasonably C22 \\
\hline & & $\begin{array}{l}\text { Blackboard-writing tidy, applying multi-media rightly } \text { C23 } \\
\text { Make goods use of time in class } \quad \text { C24 }\end{array}$ \\
\hline & $\begin{array}{l}\text { Teaching effect } \\
\text { B3 }\end{array}$ & $\begin{array}{l}\text { The study interest from students could be stimulated. Higher effect in class } \\
\text { C31 }\end{array}$ \\
\hline & & $\begin{array}{l}\text { Have guidance meaning for practice. The quality and ability for students } \\
\text { will be improved C32 }\end{array}$ \\
\hline
\end{tabular}

\section{2 Formation of judgment matrix}

When you form the judgment matrix, please reference to Table 2 as showed scaling from No.1 to No.9. Any of 2 assessment indexes can be made paired comparisons step by step so that their relative importance could be determined and give them corresponding values.

(Remark for Table 2: $\operatorname{Cij}=\{2,4,6,8,1 / 2,1 / 4,1 / 6,1 / 8\}$ refers that importance grade is between the above consecutive values.)

Table 2 1-9 Scaling

\begin{tabular}{|c|c|c|}
\hline No. & Importance Grade & Cij Value \\
\hline 1 & “i”and “j” are equally important. & 1 \\
\hline 2 & "i"is a little more important than " $\mathrm{j}$ ” & 3 \\
\hline 3 & “i”is obviously more important than “j” & 5 \\
\hline 4 & “i”is much more important than “j” & 7 \\
\hline 5 & "i"is of an extreme importance than "j" & 9 \\
\hline 6 & “j”is a little more important than "i” & $1 / 3$ \\
\hline 7 & “j”is obviously more important than "i” & $1 / 5$ \\
\hline 8 & “j”is much more important than "i”" & $1 / 7$ \\
\hline 9 & “j”is of an extreme importance than "i” & $1 / 9$ \\
\hline
\end{tabular}

Based on expert’s judgment and statistical data, the judgment matrix for each level is built. What's more, 
the corresponding weight value is calculated by applying for normalization method. As indicated in table 3 to table 6:

Table 3 Judgment Matrix A-B

\begin{tabular}{|c|c|c|c|c|}
\hline A & B1 & B2 & B3 & Weight Value (WA) \\
\hline B1 & 1 & 3 & 3 & 0.6 \\
\hline B2 & $1 / 3$ & 1 & 1 & 0.2 \\
\hline B3 & $1 / 3$ & 1 & 1 & 0.2 \\
\hline
\end{tabular}

Table $4 \quad$ Judgment Matrix B1-C

\begin{tabular}{llllll}
\hline B1 & C11 & C12 & C13 & C14 & Weight Valu(WB1) \\
\hline $\mathrm{C} 11$ & 1 & 2 & 2 & 3 & 0.4137 \\
$\mathrm{C} 12$ & $1 / 2$ & 1 & 1 & 2 & 0.2328 \\
$\mathrm{C} 13$ & $1 / 2$ & 1 & 1 & 2 & 0.2328 \\
$\mathrm{C} 14$ & $1 / 3$ & $1 / 2$ & $1 / 2$ & 1 & 0.1207 \\
\hline Remark: & $\lambda_{\max }$ & $=4.0104$, & $\mathrm{CI}=0.0035, \quad \mathrm{RI}=0.90, \quad \mathrm{CR}=0.0039<0.1$
\end{tabular}

Table 5 Judgment Matrix B2-C

\begin{tabular}{llllll}
\hline B2 & C21 & C22 & C23 & C24 & Weight Value(WB2) \\
\hline C21 & 1 & 1 & 7 & 5 & 0.4257 \\
$\mathrm{C} 22$ & 1 & 1 & 7 & 2 & 0.3345 \\
$\mathrm{C} 23$ & $1 / 7$ & $1 / 7$ & 1 & $1 / 5$ & 0.0452 \\
$\mathrm{C} 24$ & $1 / 5$ & $1 / 5$ & 5 & 1 & 0.1946 \\
\hline
\end{tabular}

Remark: $\lambda_{\max }=4.2194, \mathrm{CI}=0.0731, \mathrm{RI}=0.90, \mathrm{CR}=0.0812<0.1$

Table $6 \quad$ Judgment Matrix B3-C

\begin{tabular}{llll}
\hline B3 & C31 & C32 & Weight Value(WB3) \\
\hline C31 & 1 & 2 & 0.6667 \\
C32 & $1 / 2$ & 1 & 0.3333 \\
\hline
\end{tabular}

Remark: $\lambda_{\text {max }}=2, \mathrm{CI}=0, \mathrm{RI}=0, \mathrm{CR}=0<0.1$

\section{3 Consistency test for each level}

According to the above framed judgment matrix, the largest relative eigenvalue $\lambda_{\max }$ of each judgment matrix is calculated by Asymptotic Normalization Coefficient(ANC). Meanwhile, consistency index (CR) is also computed. As a result, all levels are satisfied with consistency.

\section{4 Total sorts of hierarchy}

As a result of calculating result of above weight value in each layer, each element of single layer to the synthesis weight vector of target level could be computed as follows.

$W A=\{W B 1(W C 11, W C 12, W C 13, W C 14), W B 2(W C 21$, 


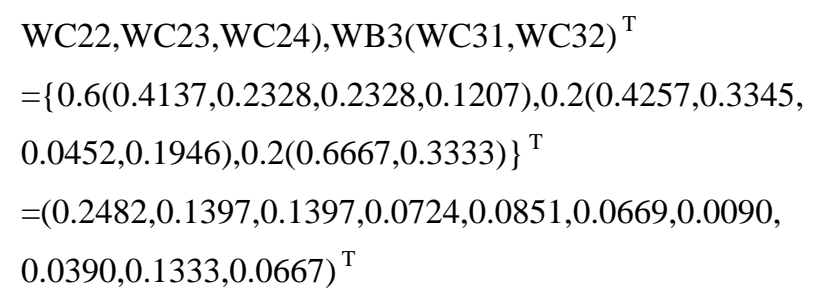

\section{Application Examples}

There are 3 teachers that are separately marked by X, Y, Z. Their teaching effect in class will be evaluated. The judges consist up experts (Quantity: M) and students (Quantity: N).Both of them take part in giving marks. The total mark is 10 scores and the weighted average is adopted. Each of teachers' weighted total scores will be come into being according to the above weight value of ten indexes. As showed by table 7 . (Table 7 for last)

From Table 7 we notice that teaching in class of 3 Teachers(X,Y,Z) are assessed by AHP teaching evaluation system so that synthetic evaluation values get a conclusion for $7.992,8.2507,8.1959$. As a result, the score of "Y" is highest among three. The score of "Z" is to be next. The score of " $\mathrm{X}$ " is the last. Therefore, we think the teaching effect of three teachers should be $\mathrm{Y}>\mathrm{Z}>\mathrm{X}$.

\section{Conclusions}

The evaluation of teaching quality in class is essential process for guaranteeing teaching quality in colleges and universities. The paper constitutes assessment hierarchy model adopted by AHP and come up with calculating methods based on analyzing for teaching appraisal index. Through examples, it proved the evaluation system can change problem of qualitative into that of quantification. The method easily computes, and its manipulation is quite convenient. Moreover, The method could mirror teaching basic index, working ability and actual state fully [5], which has definite reference meaningful for teaching quality assessment for institutions of higher education in China.

\section{References}

[1]. Du dong, Pang qinghua. Modern Integrative Assessment Approaches and Case Selects[M].Beijing: Tsinghua University Press, 2005(9) (in Chinese)

[2]. Zhao wenhui. Considering on Improving Teaching Quality Assessment Index [J].Modern Education Forum, 2009(1) (in Chinese)

[3]. Shi guojin, Chen xiaohui. The Hierarchy Structure Model of Teaching Quality Evaluated Index System for Teachers in Higher Schools[J]. Journal of Wuhan University of Technology,2000(2) (in Chinese)

[4]. Liu wei, Zhang huiping. Construction on Teaching Quality Index and Guarantee System[J]. Journal of Jilin Teachers Institute of Engineering and Technology (Social Science Edition), 2007(4) (in Chinese)

[5]. Zhao xin. Application for Teaching Quality Comprehensive Evaluation by AHP [J].. ournal of Ningxia Medical College,, 2002(2) (in Chinese) 
Table 7 Ranking Table of teachers' weighted total scores

\begin{tabular}{|c|c|c|c|c|c|c|c|c|c|c|c|c|}
\hline Index & C11 & C12 & C13 & C14 & C21 & C22 & C23 & C24 & C31 & C32 & $\begin{array}{c}\text { weight } \\
\text { ed total } \\
\text { scores }\end{array}$ & Ranking \\
\hline Weigh & 0.24 & 0.13 & 0.13 & 0.07 & 0.0851 & 0.06 & 0.00 & 0.03 & 0.13 & 0.066 & - & - \\
\hline t Value & 82 & 97 & 97 & 24 & & 69 & 9 & 9 & 33 & 7 & & \\
\hline$X$ & 8 & 9 & 7 & 8 & 8.5 & 9 & 9 & 8.5 & 7.5 & 7 & 7.992 & 3 \\
\hline $\mathrm{Y}$ & 9 & 8 & 8.5 & 7 & 7 & 8 & 9 & 8.5 & 8 & 9 & 8.2507 & 1 \\
\hline $\mathrm{Z}$ & 9 & 8.5 & 8 & 9 & 8 & 7 & 8 & 9 & 7 & 7.5 & 8.1959 & 2 \\
\hline
\end{tabular}

